\title{
Effect of Artesunate vs Memantine in Aluminum Chloride Induced Model of Neurotoxicity in Rats
}

\author{
Ahmed Shata ${ }^{1,2 *}$, Wagdi Elkashef ${ }^{3}$, Manal A. Hamouda ${ }^{2}$, Hanan Eissa1 \\ ${ }^{1}$ Department of Clinical Pharmacology, Faculty of Medicine, Mansoura University, Mansoura, Egypt \\ ${ }^{2}$ Pharmacy Practice Department, Faculty of Pharmacy, Delta University for Science and Technology, Gamasa, Egypt \\ ${ }^{3}$ Pathology Department, Faculty of Medicine, Mansoura University, Mansoura, Egypt \\ Email: *ahmedmhes@mans.edu.eg
}

How to cite this paper: Shata, A., Elkashef, W., Hamouda, M.A. and Eissa, H. (2020) Effect of Artesunate vs Memantine in Aluminum Chloride Induced Model of Neurotoxicity in Rats. Advances in Alzheimer's Disease, 9, 1-19.

https://doi.org/10.4236/aad.2020.91001

Received: February 17, 2020

Accepted: March 28, 2020

Published: March 31, 2020

Copyright $\odot 2020$ by author(s) and Scientific Research Publishing Inc. This work is licensed under the Creative Commons Attribution International License (CC BY 4.0).

http://creativecommons.org/licenses/by/4.0/

\begin{abstract}
Alzheimer disease is one of the commonest neurological diseases which is characterized by amyloid plaques accumulation in multiple brain regions. This study investigated the potential neuroprotective effect of artesunate on aluminum induced neurotoxicity vs memantine in rats. 40 male albino Wistar rats were divided randomly into 4 groups as follow: Group 1 negative control, group 2 positive control group induced by ammonium chloride, group 3 rats treated by $\mathrm{NH}_{4} \mathrm{Cl}+$ artesunate solution, group 4 rats treated by $\mathrm{NH}_{4} \mathrm{Cl}+$ memantine S.C. spatial Memory and Learning were evaluated using Morris Water Maze (MWM) test. Malondialdehyde (MDA) and reduced glutathione (GSH) levels were measured in cerebral cortex tissue homogenate. Tumor necrosis factor- $\alpha(\mathrm{TNF} \alpha)$ and interleukin-1 beta (IL-1 $\beta)$ concentrations were measured in rat cerebral cortex tissue homogenate using rat enzyme linked immunosorbent assay (ELISA) kits. Real-time quantitative reverse transcription-polymerase chain reaction (Real-time qRT-PCR) for Caspase-3, Bcl-2 and iNOS gene expression was measured in rat cerebral cortex. Slices from cerebral cortex were studied by histopathological examination. Artesunate significantly decreased MDA level and inhibited iNOS, caspase and upregulated $\mathrm{Bcl}-2$ gene expression in cerebral cortex. ART increased significantly antioxidant level GSH, and decreased significantly TNF-alpha and IL-B levels. It reduced significantly 1ry retention latency, 2ry retention latency and initial acquisition latency. It also improved brain histopathology and decreased amyloid plaque deposition. ART exerted neuroprotective effect through oxidative stress correction and enhancement of antiapoptotic markers in neuronal cells of the cerebral cortex.
\end{abstract}




\section{Keywords}

Artesunate, Memantine, Ammonium Chloride, Neurotoxicity

\section{Introduction}

Aluminum chloride $\left(\mathrm{AlCl}_{3}\right)$-induced Alzheimer disease rat model is characterized by memory loss, acetylcholine esterase hyperactivity, oxidative stress, and increased expression of amyloid $\beta$ protein markers. Also, $\mathrm{AlCl}_{3}$-induced inflammation, caspase activation, Tau pathology, changed Akt/GSK $3 \beta$ signaling pathway in cerebral cortex [1]. Exposure to $\mathrm{AlCl}_{3}$ stimulates oxidative stress markers and impairs kidney function [2].

Alzheimer disease $(\mathrm{AD})$ is a neurodegenerative disease which is characterized by cognitive and behavioral deterioration [3]. It is not a curable disease with a long preclinical period and progressive course [4]. In $\mathrm{AD}$, amyloid plaques develop in both hippocampus, and in cerebral cortex regions which are involved in thinking and making decisions. $\mathrm{AD}$ is characterized by neurofibrillary tangles (NFT) deposition of beta amyloid plaques, and neuronal cell degeneration in the brain tissue. Oxidative stress of neurons is linked also with $\mathrm{AD}$, but its link to NFT and $\beta$-amyloid protein ( $\beta$-AP) still remains uncertain [5].

Artesunate is a semi-synthetic derivative of artemisinin got from Artemisia annua which has been recognized as a medication for fever and chills in Chinese traditional system [6] [7]. It is a safe anti-malarial drug that has anthelmintic, anti-viral, anti-microbial, anti-oxidant, anti-inflammatory, anti-arthritic and anticancer properties [8] [9] [10].

Multiple studies had proved that Artemisinin (Art) is effective in treatment of inflammatory joint diseases including arthritis [11]. Also, Art has been proved to stimulate HepG2 cell apoptosis, which describes its important step in cell growth progression [12]. The phosphatidylinositol 3-kinase/AKT/mammalian target of rapamycin (PI3K/AKT/mTOR) signaling pathway plays a great role in multiple inflammatory diseases including Alzheimer disease [13]. The $\mathrm{PI} 3 \mathrm{~K} / \mathrm{AKT} / \mathrm{mTOR}$ pathway is an intracellular signaling pathway which affects cell cycle regulation as it is directly linked to cellular quiescence, proliferation and cancer [14]. An important study proved ability of Art to stimulate cell apoptosis in human cervical carcinoma through inhibiting the PI3K/AKT/ mTOR signaling pathway [15].

Memantine proved both clinical efficacy in $\mathrm{AD}$ and neuroprotective effects in laboratory studies [16]. Its use improved memory diminution in rat models of dementia [17]. Multiple studies of memantine focus mainly on its effects on neurons [18] [19]. We try in this work to explore potential neuroprotective effect of ART in Aluminum chloride $\left(\mathrm{AlCl}_{3}\right)$-induced Alzheimer disease rat model and explain its underlying mechanisms in comparison with memantine as standard drug for $\mathrm{AD}$. 


\section{Chemicals and Drugs}

Aluminum chloride anhydrous (molecular weight: $133.332 \mathrm{~g} / \mathrm{mol}$ ) was purchased from El-Gomhouria Chemical Company, Mansoura, Egypt. Memantine hydrochloride was used in the study (manufactured by Lundbeck company, Denmark), Artesunate solution (manufactured by Actiza pharmaceutical, India).

\section{Experimental Design}

40 Male albino Wistar rats (weighing 150 - 160 gm) were obtained from the animal house of Faculty of Pharmacy, Mansoura University, Egypt. The rats were housed in standard cages where food and water were provided ad libitum. After acclimation period, they were randomly divided into 4 groups (10 for each).

Group 1 Negative control rats receive a normal saline.

Group 2 Positive control group induced by aluminum chloride $\left(\mathrm{AlCl}_{3}, 100\right.$ $\mathrm{mg} / \mathrm{kg}$ b.w.) intraperitoneally for 6 weeks [20].

Group 3 rats treated by $\mathrm{AlCl}_{3}$ as above + artesunate solution $(\mathrm{pH}=6.0 ; 3$ $\mathrm{mg} / \mathrm{kg}$,i.p.) once a day for 6 weeks [21].

Group 4 rats treated by $\mathrm{AlCl}_{3}$ as above + memantine S.C. (10 mg/kg/day) [22] for 6 weeks.

\subsection{Evaluation of Spatial Memory and Learning by Morris Water Maze (MWM) Test}

Morris Water Maze is formed of a big round pool (its diameter is $150 \mathrm{~cm}$, its height is $45 \mathrm{~cm}$ ) filled with water at $26^{\circ} \mathrm{C}$ to $30 \mathrm{~cm}$ depth and divided into four equivalent quadrants by two fixed strands at right angles. The pool was put in an illumined test room. In each pool quadrant, a circular platform (its diameter is $4.5 \mathrm{~cm}$ ) was placed, $1 \mathrm{~cm}$ above the water level by $1 \mathrm{~cm}$ during the acquisition stage and during the retention stage, the platform was situated below the water level by $1 \mathrm{~cm}$. The platform position was constant in the same quadrant during evaluation of each stage [23]. The water was made opaque (white) during the retention phase by adding powdered milk. During the test the rats were trained to jump onto platform not to swim for 60 seconds and by time the rats will learn the spatial platform site from any beginning site at the pool circumference [24].

\subsection{Maze Acquisition Phase}

On Day 20, rats were trained four times with 5 minutes interval in between. A trial was done by introducing the rat into the maze fronting the pool wall and the delay to jump to the platform was noted for 90 seconds. If the rat did not jump onto the platform within 90 seconds, it was directed to the platform and kept there for 20 seconds. The initial acquisition latency (IAL) was defined as the time consumed by the rat to jump on the platform [25].

\subsection{Maze Retention Phase}

After the four training sessions, the time spent to reach the hidden platform (re- 
tention latency "RL") was calculated on day 21 ( $\left.1^{\text {st }} R L\right)$ and day $42\left(2^{\text {nd }} R L\right)$. The change in RL from day 21 to day 42 was estimated to test for acquired memory.

During the retention phase, the platform was removed from the pool and each rat was given up for 60 seconds to search for the position of the missing platform (four trials/day for three days). Several parameters were extracted from the retention phase data including time spent in the target quadrant, time spent in non-target quadrants and the number of passes over the missing platform site [26].

\subsection{Brain Tissue Sampling and Preparation}

When the study was finished, all rats were weighed and feed deprived for $24 \mathrm{~h}$. Rats were anesthetized using thiopental sodium $(40 \mathrm{mg} / \mathrm{kg}$, ip of $2.5 \%$ thiopental) that was supplied in the form of (Anapental $500 \mathrm{mg} / \mathrm{vial}$ ) and was purchased from Sigma Tec Co., Egypt [27]. Rats were sacrificed by decapitation and the skull was opened and each rat brain was quickly removed and cut mid-sagittally into two hemispheres.

\subsection{Cerebral Cortex Hemisphere from Rats of Each Group Were Used as Follows}

One cerebral cortex hemisphere was cleaned with ice-cold saline to eliminate blood, quickly kept in Eppendorf tubes, embedded in liquid nitrogen and stored at $-80^{\circ} \mathrm{C}$ for quantitative Real-time polymerase chain reaction (RT-PCR). The other cerebral cortex hemisphere was kept in $10 \%$ neutral buffered formalin to be fixed and then examined histopathologically by hematoxylin and eosin and silver stain.

\subsection{Biochemical Estimations}

Rat cerebral cortex tissue homogenate was used to evaluate malondialdehyde (MDA) and reduced glutathione (GSH) levels using Bio-diagnostic kit (Egypt). Also, tumor necrosis factor alpha (TNF- $\alpha$ ) and interleukin-1 beta (IL-1 $\beta$ ) concentrations were estimated in rat cerebral cortex tissue homogenate using rat enzyme linked immunosorbent assay (ELISA) kits (Ray Bio Rat TNF-alpha and IL- $1 \beta$ ELISA Kit, USA).

\subsection{Histopathological Examination}

Rat cerebral cortex specimens were kept in $10 \%$ formalin for $24 \mathrm{~h}$ to be fixed and cleaned with water. Sequential alcohol dilutions were used for desiccation. Specimens were cleaned in xylene immersed in paraffin in hot air oven at $56^{\circ} \mathrm{C}$ for 24 h. Paraffin bees wax tissue block preparation was performed to be divided by microtome at 4 microns thickness. The resulting tissue slices were put on glass slides, cleared from paraffin and stained with hematoxylin and eosin stain for histopathological examination under light microscopy [28] and silver stain for the senile plaques and neurofibrillary tangles. 


\subsection{Real-Time Quantitative Reverse Transcription-Polymerase Chain Reaction (Real-Time qRT-PCR) for Caspase-3, Bcl-2 and iNOS Gene Expression Determination in Rat Cerebral Cortex}

Total RNA was isolated from cerebral cortex using RNeasy Mini kit (Qiagen, Valencia, CA, USA). Purity and concentration of each RNA sample were measured spectrophotometrically using 260 and $260 / 280 \mathrm{~nm}$ ratio respectively, using NanoDrop ${ }^{\oplus}$ ND-1000 Spectrophotometer (NanoDrop Technologies, Wilmington, Delaware, USA). Purity of each RNA sample was calculated and ranged between 1.8 and 2.1 demonstrating high purity of the RNA. mRNA levels were measured by real-time quantitative RT-PCR. All PCR reactions were done in 25 $\mu \mathrm{l}$ as total volume and included the following components: cDNA derived from $25 \mathrm{ng}$ of total RNA, $400 \mathrm{nM}$ of each primer (Table 1), RNase-free water, and $12.5 \mu \mathrm{l}$ of SYBR Green PCR Master Mix (ABI), an optimized buffer system containing AmpliTaq Gold DNA polymerase and dNTPs. All PCR reactions were done in duplicate and cycling parameters were as follows: after an initial denaturation step for $10 \mathrm{~min}$ at $95^{\circ} \mathrm{C}, 40$ subsequent cycles were performed in which samples were denatured for $15 \mathrm{~s}$ at $95^{\circ} \mathrm{C}$ followed by primer annealing and elongation at $60^{\circ} \mathrm{C}$ for $1 \mathrm{~min}$. The relative quantities of mRNA were normalized by GAPDH. Relative quantification of mRNA expression was calculated with the 2- $\Delta \Delta \mathrm{Ct}$ method [29] [30]. The data were presented as relative quantity (RQ) of target mRNA, normalized respect to GAPDH mRNA and relative to a calibrator sample. Normal control samples were used as calibrators. Where: $\Delta \mathrm{Ct}=(\mathrm{Ct}$ of target gene $-\mathrm{Ct}$ of reference gene $), \Delta \Delta \mathrm{Ct}=(\Delta \mathrm{Ct}$ of sample $-\Delta \mathrm{Ct}$ of control, normal, non-diseased). $\mathrm{Ct}$ is defined as the fractional cycle number at which the fluorescence passes the fixed threshold.

\subsection{Statistical Analysis}

Statistical analysis was done using The Statistical Package for Social Science (SPSS) program version 13. Data of biochemical parameters were presented as mean \pm SD. Differences among groups within the experiment were analyzed by the one-way ANOVA test followed by post hoc Tukey test. P-value $<0.05$ value was considered significant.

Table 1. Primers sets used in quantitative RT-PCR (Biosearch technologies, CA, USA).

\begin{tabular}{cc}
\hline Name & Sequence \\
\hline GAPDH Forward & 5'-CCATCAACGACCCCTTCATT-3' \\
GAPDH Reverse & 5'-CACGACATACTCAGCACCAGC-3' \\
Caspase-3 Forward & 5'-GTGGAACTGACGATGATATGGC-3' \\
Caspase-3 Reverse & 5'-CGCAAAGTGACTGGATGAACC-3' \\
Bcl-2 Forward & 5'-TGTGGATGACTGACTACCTGAACC-3' \\
Bcl-2 Reverse & 5'-CAGCCAGGAGAAATCAAACAGAGG-3' \\
iNOS forward & 5'-ACAACGTGGAGAAAACCCCAGGTG-3' \\
iNOS Reverse & 5'-ACAGCTCCGGGCATCGAAGACC-3' \\
\hline
\end{tabular}




\section{Results}

In Table 2, both medication exert a significant inhibitory effect on iNOS ( $\mathrm{p}<$ $0.006, \mathrm{p}<0.002$ respectively). Also, both medications significantly alter caspase levels ( $\mathrm{p}<0.004, \mathrm{p}<0.002$ respectively) and Bcl-2 ( $\mathrm{p}<0.005, \mathrm{p}<0.002$ respectively).

In Table 3, both medications reduce significantly 1ry retention latency, 2ry retention latency and initial acquisition latency in comparison to positive control group. Only memantine exert a significant amelioration of object recognition.

In Table 4, both artesunate and memantine cause a significant reduction of IL-B ( $\mathrm{p}<0.002, \mathrm{p}<0.001$ respectively). Also they reduce significantly TNF- $\alpha$ ( $\mathrm{p}$ $<0.004, \mathrm{p}<0.001$ respectively). On the other hand, they improve significantly GSH ( $\mathrm{p}<0.006, \mathrm{p}<0.001$ respectively). Both medications, artesunate and memantine significantly decrease the levels of MDA ( $p<0.005, p<0.001)$ in comparison to positive control group.

Table 2. Effect of memantine and artesunate on relative quantification (RQ) of caspase 3, iNOS and BCl-2 mRNA gene expression in cerebral cortex of aluminum chloride $\left(\mathrm{AlCl}_{3}\right)$ treated rats (mean $\pm \mathrm{SD}$ ).

\begin{tabular}{cccc}
\hline & Caspase 3 & iNOS & Bcl-2 \\
\hline Group 1 & $0.99 \pm 0.33^{\mathrm{p} 1}$ & $1.01 \pm 0.11^{\mathrm{p} 1}$ & $1.1 \pm 0.06^{\mathrm{p} 1}$ \\
Group 2 & $2.71 \pm 0.51$ & $2.5 \pm 0.17$ & $0.48 \pm 0.10$ \\
Group 3 & $1.4 \pm 0.36^{\mathrm{p} 1, \mathrm{p} 2}$ & $1.5 \pm 0.51^{\mathrm{p} 1, \mathrm{p} 2}$ & $0.84 \pm 0.23^{\mathrm{p} 1}$ \\
Group 4 & $1.6 \pm 0.45^{\mathrm{p} 1, \mathrm{p} 2}$ & $1.9 \pm 0.48^{\mathrm{p} 1, \mathrm{p} 2}$ & $0.89 \pm 0.43^{\mathrm{p} 1}$ \\
\hline
\end{tabular}

P1 significance vs group 2; P2 significance vs group 1.

Table 3. Effect of memantine and artesunate on memory function in spatial navigation task of Morris Water Maze (MWM) test and object recognition test in aluminum chloride $\left(\mathrm{AlCl}_{3}\right)$-treated rats (mean $\left.\pm \mathrm{SD}\right)$.

\begin{tabular}{ccccc}
\hline & $\begin{array}{c}\text { Initial acquisition } \\
\text { latency }\end{array}$ & $\begin{array}{c}\text { 1ry } \\
\text { retention latency }\end{array}$ & $\begin{array}{c}\text { 2ndy } \\
\text { retention latency }\end{array}$ & $\begin{array}{c}\text { Object } \\
\text { recognition Test }\end{array}$ \\
\hline Group 1 & $16.9 \pm 2.7^{\mathrm{p} 1}$ & $12.3 \pm 7.92^{\mathrm{p} 1}$ & $8.6 \pm 2.01^{\mathrm{p} 1}$ & $75.7 \pm 16.5^{\mathrm{p} 1}$ \\
Group 2 & $69.2 \pm 22.4$ & $78.2 \pm 21.3$ & $53.4 \pm 23.7$ & $39.1 \pm 13.9$ \\
Group 3 & $36.2 \pm 6.4^{\mathrm{p} 1, \mathrm{p} 2}$ & $32.9 \pm 8.1^{\mathrm{p} 1, \mathrm{p} 2}$ & $35 \pm 11.2^{\mathrm{p} 1, \mathrm{p} 2}$ & $52.5 \pm 12.4^{\mathrm{p} 2}$ \\
Group 4 & $27.4 \pm 6.5^{\mathrm{p} 1}$ & $28 \pm 11.9^{\mathrm{p} 1}$ & $23.2 \pm 11.4^{\mathrm{p} 1}$ & $64 \pm 9.1^{\mathrm{p} 1}$ \\
\hline
\end{tabular}

P1 significance vs group 2; P2 significance vs group 1.

Table 4. Effect of memantine and artesunate on GSH, MDA, tumor necrosis factor- $\alpha$ $($ TNF- $\alpha$ ) and interleukin- $1 \beta$ (IL-1 $\beta$ ) concentrations in cerebral cortex tissue homogenate of aluminum chloride $\left(\mathrm{AlCl}_{3}\right)$-treated rats (mean $\left.\pm \mathrm{SD}\right)$.

\begin{tabular}{ccccc}
\hline & $\begin{array}{c}\text { GSH } \\
(\mathrm{mg} / \mathrm{dl})\end{array}$ & $\begin{array}{c}\text { TNF- } \alpha \\
(\mathrm{pg} / \mathrm{ml})\end{array}$ & $\begin{array}{c}\text { IL-B } \\
(\mathrm{pg} / \mathrm{ml})\end{array}$ & $\begin{array}{c}\text { MDA } \\
(\mathrm{nmol} / \mathrm{ml})\end{array}$ \\
\hline Group 1 & $14.95 \pm 2.7^{\mathrm{pl}}$ & $12.12 \pm 2.2^{\mathrm{p} 1, \mathrm{p} 2}$ & $38.1 \pm 5.4^{\mathrm{p} 1}$ & $9.95 \pm 0.96^{\mathrm{p}^{1}}$ \\
Group 2 & $5.9 \pm 1.01$ & $23.8 \pm 2.7$ & $84.9 \pm 10.6$ & $15.7 \pm 2.2$ \\
Group 3 & $12.89 \pm 1.34^{\mathrm{p} 1}$ & $14.5 \pm 3.9^{\mathrm{pl}}$ & $50.5 \pm 6.6^{\mathrm{pl}, \mathrm{p} 2}$ & $11.9 \pm 1.1^{\mathrm{pl}, \mathrm{p} 2}$ \\
Group 4 & $13.11 \pm 1.2^{\mathrm{p} 1}$ & $13.2 \pm 2.12^{\mathrm{p} 1}$ & $46.9 \pm 6.2^{\mathrm{p} 1}$ & $11.33 \pm 0.87^{\mathrm{p} 1}$ \\
\hline
\end{tabular}

P1 significance vs group 2; P2 significance vs group 1. 


\section{Effect of Memantine or Artesunate on Histopathological Examination in Cerebral Cortex of Aluminum Chloride $\left(\mathrm{AlCl}_{3}\right)$-Treated Rats}

Figure 1 and Figure 2 show normal cerebral cortex brain tissue with no detected microscopic abnormalities. Examination of the cerebral cortex of $\mathrm{AlCl}_{3}$ group by hematoxylin and eosin revealed areas of brain cell apoptosis (Figure 3 and Figure 4). Histopathological results of $\mathrm{AlCl}_{3}+$ artesunate treated group showed normal cerebral cortex brain cellularity and normal thickness of the blood vessels with no amyloid plaques detected neither in hematoxylin and eosin-stained slides nor in silver stain slides (Figure 5 and Figure 6). Examination of the cerebral cortex of $\mathrm{AlCl}_{3}+$ Memantine group by hematoxylin and eosin and silver stain revealed more or less normal cerebral cortex brain tissue with normal brain cellularity and normal thickness of the cerebral cortex blood vessels when compared to $\mathrm{AlCl}_{3}$ group. No amyloid plaques were detected neither in hematoxylin and eosin-stained or silver stained slides (Figure 7 and Figure 8).

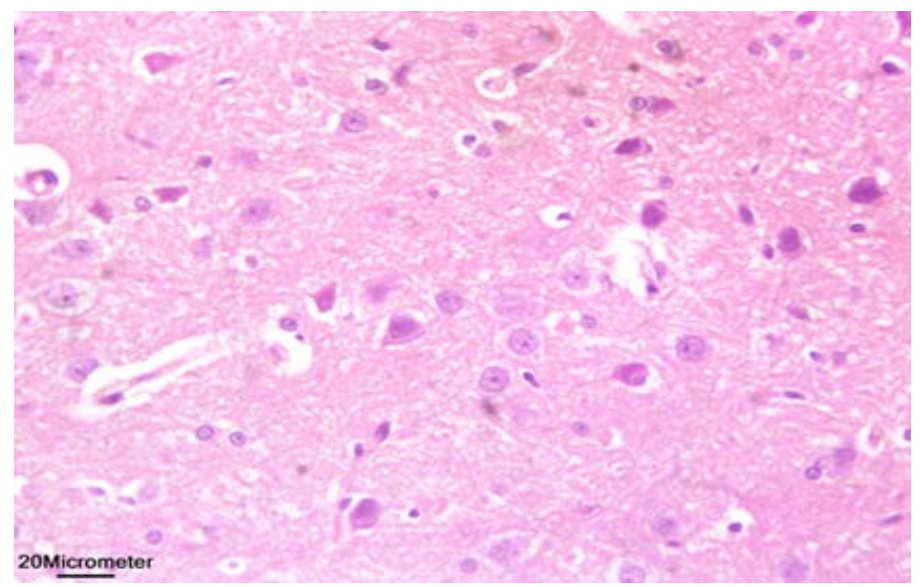

Figure 1. Control group's hematoxylin and eosin-stained section $(\times 400)$ revealed normal cerebral cortex brain tissue with no detected microscopic abnormalities.

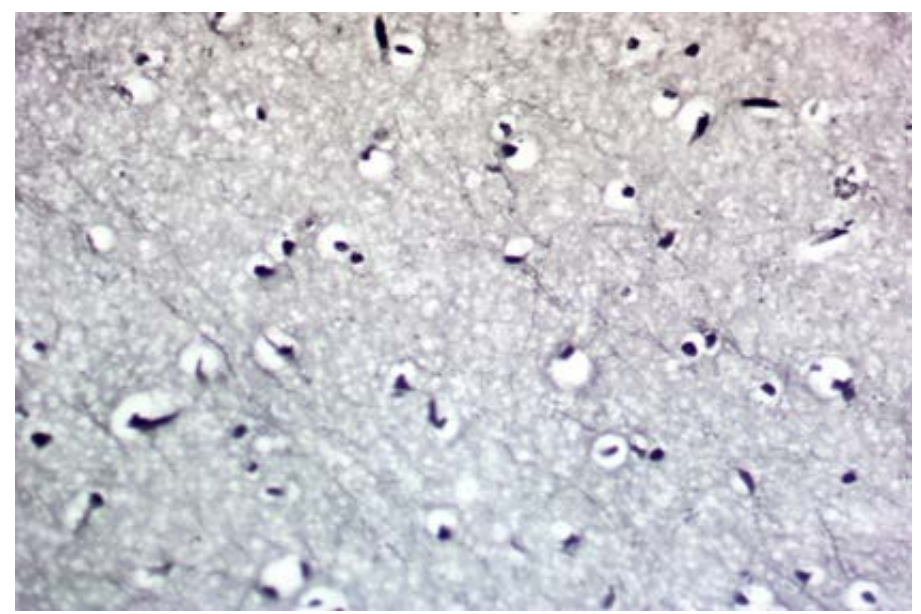

Figure 2. Control group's silver-stained section $(\times 400)$ revealed normal cerebral cortex brain tissue with no detected microscopic abnormalities. 


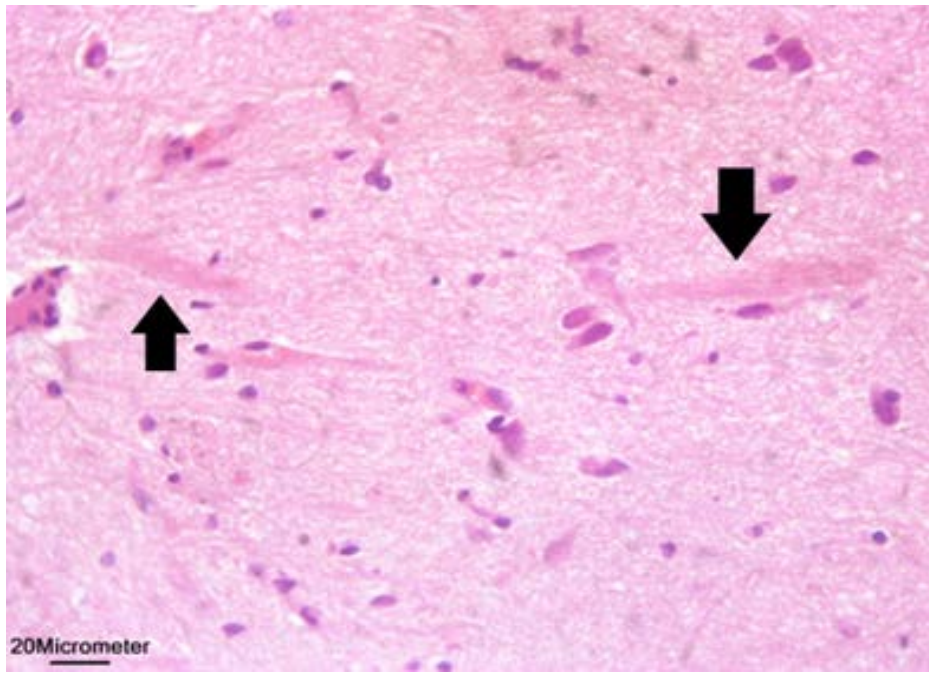

Figure 3. $\mathrm{AlCl}_{3}$ group's hematoxylin and eosin-stained section $(\times 400)$ revealed multiple apoptotic bodies (tip of black arrows).

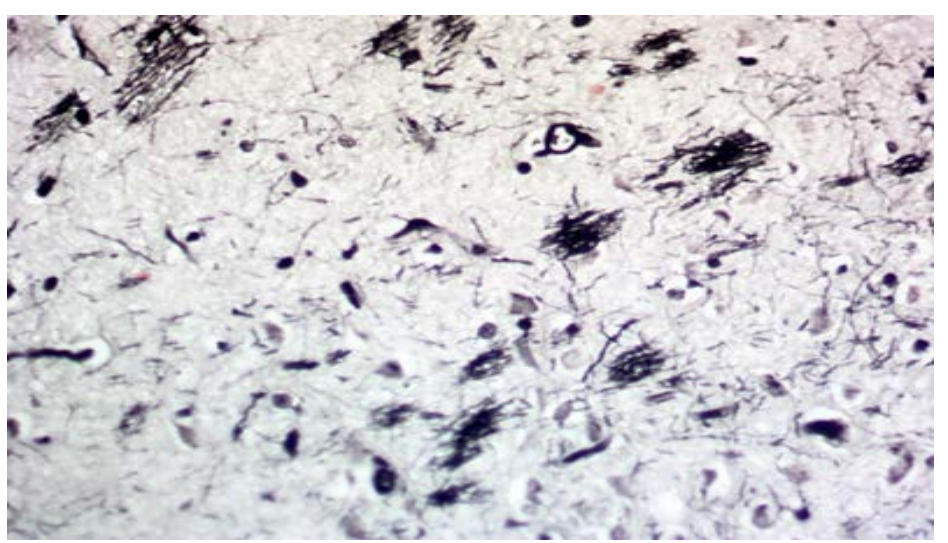

Figure 4. $\mathrm{AlCl}_{3}$ group's silver-stained section $(\times 400)$ revealed multiple apoptotic bodies.

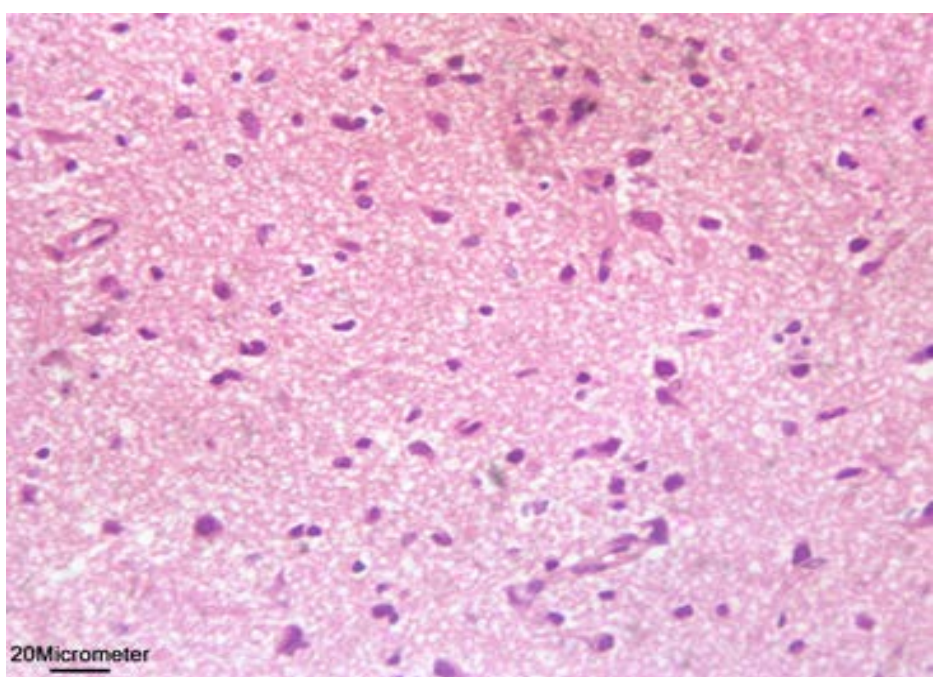

Figure 5. $\mathrm{AlCl}_{3}+$ Artesunate treated group's hema-toxylin and eosin-stained sections $(\times 400)$ revealed more or less normal cerebral cortex brain tissue with normal cellularity and normal thickness of the blood vessels. No amyloid plaques were detected. 


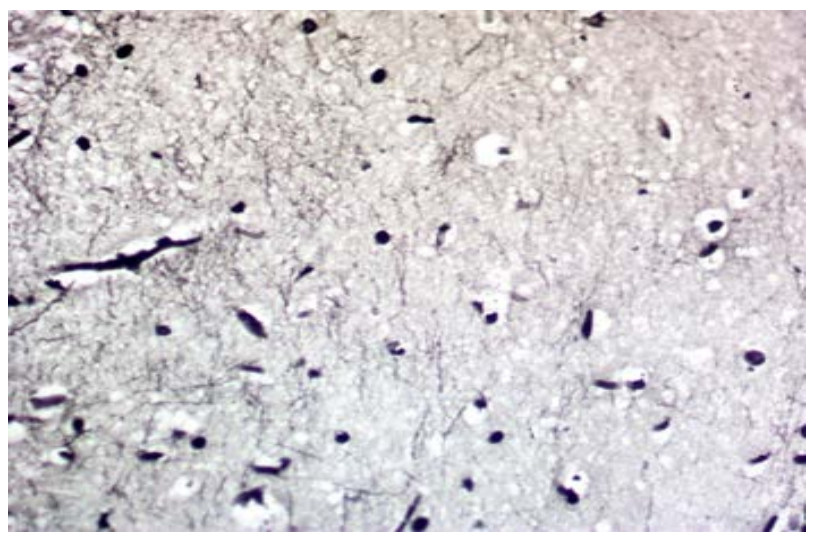

Figure 6. $\mathrm{AlCl}_{3}+$ Artesunate treated group's silver-stained sections $(\times 400)$ revealed more or less normal cerebral cortex brain tissue with normal cellularity and normal thickness of the blood vessels. No amyloid plaques were detected.

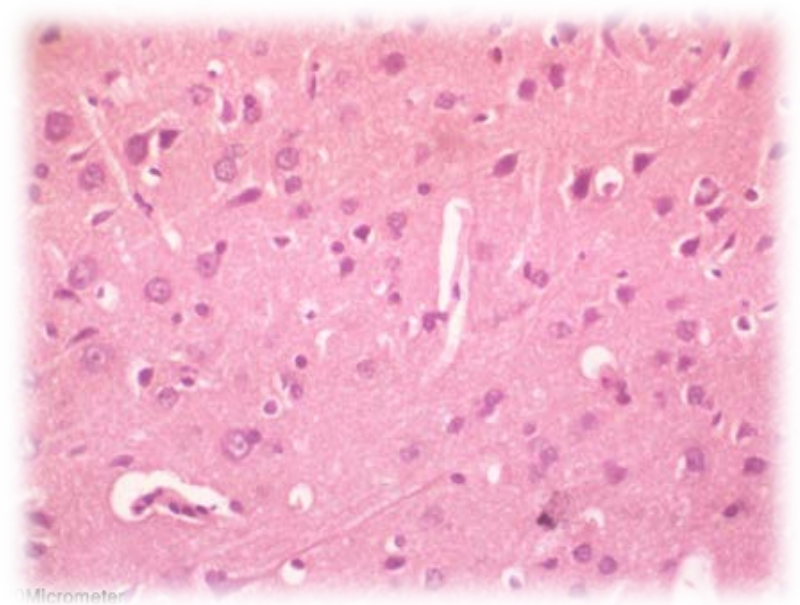

Figure 7. $\mathrm{AlCl}_{3}+$ Memantine group's hematoxylin and eosin-stained sections $(\times 400)$ revealed more or less normal cerebral cortex brain tissue with normal cellularity and normal thickness of the blood vessels. No amyloid plaques were detected.

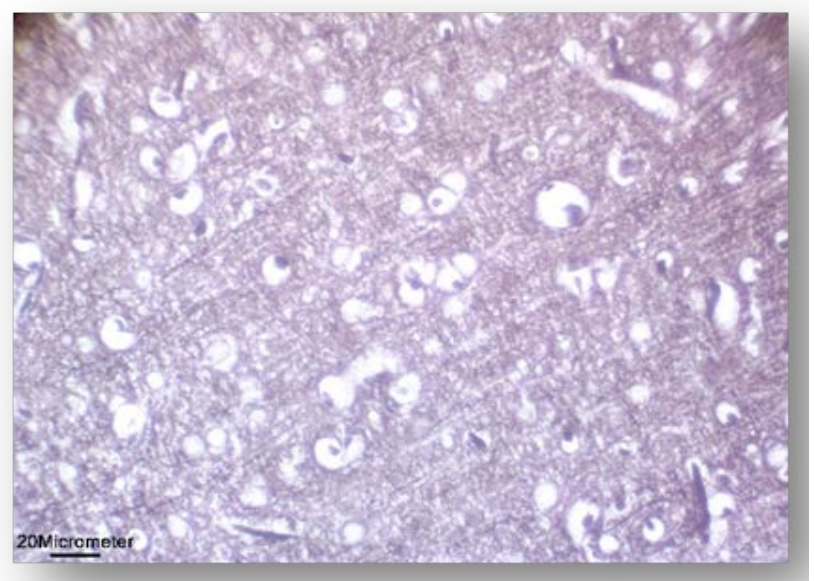

Figure 8. $\mathrm{AlCl}_{3}+\mathrm{Memantine}$ group's silver stained sections $(\times 400)$ revealed more or less normal cerebral cortex brain tissue with normal cellularity and normal thickness of the blood vessels. No amyloid plaques were detected. 


\section{Discussion}

Alzehimer disease is considered one of the commonest disabling neurological diseases worldwide. Multiple pathological processes are suggested to explain its mechanism and many drugs are generated to fight the disease and postpone cognitive functions decline but with limited outcome.

Results of our study confirmed that aluminum chloride $\left(\mathrm{AlCl}_{3}\right)$ administration in rats for 6 weeks led to impairment of both spatial learning and memory evidenced by $\mathrm{MWM}$. $\mathrm{AlCl}_{3}$-treated rats showed a significant delay in time taken to jump onto the platform in both maze acquisition and retention phases when compared to control rats. These results are consistent with several studies [31] [32] [33]. Impaired cognition after aluminum chloride administration may be caused by $\mathrm{Al}^{3+}$ accumulation in neuronal cells [34].

In contrast, co-administration of memantine or artesunate with $\mathrm{AlCl}_{3}$ for 6 weeks to rats significantly improved spatial learning and memory impairment as shown by a significant decline in the MWM test's 1st and 2nd RLs when compared to $\mathrm{AlCl}_{3}$-treated rats. Several studies proved that memantine enhanced memory and cognition by MWM test [35] [36] [37]. Memantine is a non-competitive NMDA receptor antagonist and reduces also elevated AChE enzyme activity [38]. In the current study, memantine also significantly decreased cerebral cortex TNF- $\alpha$ and IL- $1 \beta$ concentrations.

Artesunate reduced 1ry retention latency, 2ry retention latency and initial acquisition latency and improved cognitive function and decreases its delay. The Morris test was done for cognition examination [39]. Artesunate cognitive enhancing effect might be due to its anti-inflammatory effect proved by significant reduction incerebral cortex TNF- $\alpha$, IL- $1 \beta$ levels. Multiple previous studies demonstrated anti-inflammatory effect of artesunate in different animal models [40].

The current study proved that $\mathrm{AlCl}_{3}$ administration in rats for 6 weeks elevated cerebral cortex TNF- $\alpha$ and IL- $1 \beta$ concentrations in comparison to control rats. These data are consistent with multiple studies in rats [41] [42] and mice [43]. In addition, TNF- $\alpha$ and IL- $1 \beta$ concentrations were increased also in both brains and plasma of AD patients [44] [45].

$\mathrm{AlCl}_{3}$ is responsible for induction of neuroinflammation and inflammatory cytokine production e.g. TNF- $\alpha$, IL- $1 \beta$, IL- 6 due to maintained stimulation of microglia in a feed forward circuit through a process called reactive microgliosis. Also, $\mathrm{Al}^{3+}$ activates nuclear factor-kappa $\mathrm{B}(\mathrm{NF}-\kappa \mathrm{B})$, mitogen-activated protein kinase/activator protein-1, and hypoxia inducible factor-1 (HIF-1), which are responsible for neuroinflammation [46]. Also, it maintained release of pro-inflammatory cytokines and neurotoxins from microglia which is responsible for neuroinflammation exacerbation. Aluminium chloride accumulation in the cerebral cortex causes abnormal deposition of $\mathrm{A} \beta$ which stimulates several inflammatory components [47].

The current study proved that individual administration of memantine or artesunate with $\mathrm{AlCl}_{3}$ in rats resulted in significant reduction of cerebral cortex 
TNF- $\alpha$, IL- $1 \beta$ concentrations in comparison to $\mathrm{AlCl}_{3}$-treated rats. Several studies using memantine are consistent with our study results [48] [49]. Explanation for cerebral cortex TNF- $\alpha$ and IL- $1 \beta$ concentrations reduction by memantine administration is due to inhibition of NF- $\kappa$ B pathway and blockade of NMDA receptor [50].

In inflammatory diseases, ART proved to be beneficial in inhibition of COX-2 gene expression, maintainance of oxidative homeostasis, reduction of TNF- $\alpha$ level, interleukins and inhibition of NF- $\kappa \mathrm{B}$ mediated signaling pathway [51]. ART had renoprotective effect through reduction of tubulointerstitial inflammation and fibrosis in rats [52]. So, due to its anti inflammatory properties, ART had been used in management of multiple inflammatory diseases like hepatic fibrosis [53], lung fibrosis, renal fibrosis [54] and epidural fibrosis through inhibition of Toll-like receptor 4 (TLR4)-nuclear factor (NF)- $\kappa$ B pathway [55]. Finally, administration of artesunate for 8 days decreased serum TNF- $\alpha$ levels and inhibited lipopolysachaarides (LPS)-induced inflammatory bone loss in vivo [56].

The current study proved $\mathrm{AlCl}_{3}$ administration in rats for 6 weeks elevated cerebral cortex MDA level and decresed GSH level in comparison to control group. Oxidative stress is defined as imbalance between ROS and antioxidant defense. This imbalance plays an important role in multiple neurodegenerative diseases. Several studies proved that oxidative stress is characteristic sign of AD. In addition, inhibition of antioxidative systems stimulated free radicals production which share in neuronal damage [57]. In the current work, both memantine and artesunate increased significantly antioxidant level of GSH, and decreasee significantly MDA level in cerebral cortex, ART could inhibit reactive oxygen species geneartion in vitro studies [40]. Malondialdehyde is considered an end product of lipid peroxidation which produces cytotoxicity and its concentration can reflect the degree of cell damage. The present study proved that artesunate decreased MDA level by reduction of lipid peroxidation. This finding was consistent with the results of [58] [59]. The results of the above experiments were in agreement also with previous studies [59] [60] which proved that artemisin improved the GSH-level as it contains flavonoids materials and polysaccharides which had antioxidant effect and a free radical scavenging ability [61].

Alzehimer disease is linked to apoptosis process through abnormal gene expression of Bcl-2, Bax and caspase-3. Bcl-2 inhibits apoptosis to protect cell survival, rather than cell proliferation promotion through mitochondrial membrane stabilization and prevention of caspases and cytochrome $c$ release [62]. Also, Bax inhibits $\mathrm{Bcl}-2$ expression and stimulates cytochrome $\mathrm{c}$ release, thus activating caspases and inducing process of apoptosis [63]. So, Bcl-2 and Bax modulatory effects on apoptosis are in opposition.

The current study's results confirmed that continuous $\mathrm{AlCl}_{3}$ administration in rats significantly increased mRNA expression of caspase 3, iNOS mRNA gene expression in cerebral cortex when compared to control rats. Earlier studies had demonstrated similar results with increased mRNA expression [63] [64] as $\mathrm{AlCl}_{3}$ causes apoptotic neuronal loss by stimulating ROS generation, which is a cha- 
racteristic symptom of neurodegeneration [65]. It also stimulares neurons and astrocytes apoptosis through caspases activation in rodent and in vitro models [64]. Caspase-induced apoptosis had been recognized in Amyloid- $\beta$-induced Alzheimer's and 6-hydroxydopamine-induced Parkinson's neurodegeneration [66] [67]. Our study results findings are consistent with some studies which explain the role of artesunate supplementation to nitrosodiethylamine treated models of animals in up-regulation of Bcl-2 and down-regulation of Caspase-3 gene expression [68]. This confirms neuroprotective role of artesunate in decreasing apoptosis biomarkers which increased markedly in $\mathrm{AD}$, beside its role in attenuation of oxidative stress markers.

ART plays an important role in protection of multiple tissue through pleitropic mechanisms. As regard pancreatic tissue beta cells, it reduced its apoptosis and inhibited elevation of NF- $\kappa \mathrm{B}$, iNOS expression, and NO production [69]. Moreovere, the expressions of PPAR- $\gamma$, p 53 and Caspase 3 decreased markedly by ART in hepatic stellate cells [5].

This study results were confirmed by histopathological examination of cerebral cortex from different rat groups stained with hematoxylin and eosin and silver stains. Examination of cerebral cortex tissue of $\mathrm{AlCl}_{3}$ treated rats stained with hematoxylin and eosin revealed amyloid plaques and degenerative changes compared to control rats. Similar earlier studies had shown similar results of amyloid plaques in $\mathrm{AlCl}_{3}$ model of $\mathrm{AD}$ [70] [71].

Our study is consistent with [72] who stated that the presence of even a few tangles in a single field in cerebral cortex suggests a significant cognitive decline and is compatible with the diagnosis of $\mathrm{AD}$ made on the basis of clinical findings. They added that the numbers of tangles increase as cognitive decline increases. In addition, Nobakht et al. [70] observed that the criteria for neuropathological diagnosis of $\mathrm{AD}$ take into account the NFTs and senile plaques formation.

Histopathoplogical examination of cerebral cortex tissue of $\mathrm{AlCl}_{3}$ and memantine treated rats revealed more or less normal cerebral cortex brain tissue when compared to $\mathrm{AlCl}_{3}$-treated rats. Also, no amyloid plaques were detected. These results are in agreement with several studies that showed memantine lowering effect on amyloid plaques [73] [74].

Examination of cerebral cortex tissue of $\mathrm{AlCl}_{3}$ and artesunate in treated rats stained with hematoxylin and eosin stain or silver stain showed similar results to $\mathrm{AlCl}_{3}$ and memantine co-treated rats. Histopathological changes in cerebral cortex brain tissue in different rat groups may be explained by the biochemical and transcriptional gene expression changes which are previously discussed.

\section{Conclusion}

ART exerted neuroprotective effect against ammonium chloride neurotoxicity and behavioral parameters including cognitive deficits. The biochemical changes were reversed through correction of oxidative stress and amelioration of antiapoptotic biomarkers in neuronal cells of the cerebral cortex. It also improves 
the pathological structures. ART can ameliorate multiple pathological defects in this model of neurotoxicity but further clinical studies are required to confirm these results.

\section{Conflicts of Interest}

The authors declare no conflicts of interest regarding the publication of this paper.

\section{References}

[1] Justin-Thenmozhi, A., Dhivya Bharathi, M. and Kiruthika, R. (2018) Attenuation of Aluminum Chloride-Induced Neuroinflammation and Caspase Activation through the AKT/GSK-3 $\beta$ Pathway by Hesperidin in Wistar Rats. Neurotoxicity Research, 34, 463-476. https://doi.org/10.1007/s12640-018-9904-4

[2] Liu, Y., Huang, G., Mo, B. and Wang, C. (2017) Artesunate Ameliorates Lung Fibrosis via Inhibiting the Notch Signaling Pathway. Experimental and Therapeutic Medicine, 14, 561-566. https://doi.org/10.3892/etm.2017.4573

[3] Querfurth, H.W. and LaFerla, F.M. (2010) Alzheimer's Disease. The New England Journal of Medicine, 362, 329-344. https://doi.org/10.1056/NEJMra0909142

[4] Anand, R., Kaushal, A., Wani, W.Y., et al. (2012) Road to Alzheimer's Disease: The Pathomechanism Underlying. Pathobiology, 79, 55-71.

https://doi.org/10.1159/000332218

[5] Du, Y., Li, L.N. and Fang, B.W. (2015) Effects of Artesunate on Hepatic Fibrosis and Its Mechanism. Chinese Journal of Applied Physiology, 31, 14-17.

[6] Rosenthal, P.J. (2008) Artesunate for the Treatment of Severe Falciparum Malaria. The New England Journal of Medicine, 358, 1829-1836.

https://doi.org/10.1056/NEJMct0709050

[7] Tsuda, K., Miyamoto, L., Hamano, S., et al. (2018) Mechanisms of the pH- and Oxygen-Dependent Oxidation Activities of Artesunate. Biological and Pharmaceutical Bulletin, 41, 555-563. https://doi.org/10.1248/bpb.b17-00855

[8] Callender, D.M. and Hsue, G. (2011) Artesunate: Investigational Drug for the Treatment of Severe Falciparum Malaria in Hawai'i. Hawaii Medical Journal, 70, 77-79.

[9] Verma, S., Das, P. and Kumar, V.L. (2017) Chemoprevention by Artesunate in a Preclinical Model of Colorectal Cancer Involves Down Regulation of $\beta$-Catenin, Suppression of Angiogenesis, Cellular Proliferation and Induction of Apoptosis. Chemico-Biological Interactions, 278, 84-91. https://doi.org/10.1016/j.cbi.2017.10.011

[10] Shakeri, A., Amini, E., Asili, J., et al. (2018) Screening of Several Biological Activities Induced by Different Sesquiterpene Lactones Isolated from Centaurea behen L. and Rhaponticum repens (L.) Hidalgo. Natural Product Research, 32, 1436-1440. https://doi.org/10.1080/14786419.2017.1344661

[11] Guruprasad, B., Chaudhary, P., Choedon, T., et al. (2015) Artesunate Ameliorates Functional Limitations in Freund's Complete Adjuvant-Induced Monoarthritis in Rat by Maintaining Oxidative Homeostasis and Inhibiting COX-2 Expression. Inflammation, 38, 1028-1035. https://doi.org/10.1007/s10753-014-0067-z

[12] Qin, G., Wu, L., Liu, H., et al. (2015) Artesunate Induces Apoptosis via a ROS-Independent and Bax-Mediated Intrinsic Pathway in HepG2 Cells. Experimental Cell 
Research, 336, 308-317. https://doi.org/10.1016/j.yexcr.2015.07.004

[13] Li, P.P., Liu, D.D., Liu, Y.J., et al. (2012) BAFF/BAFF-R Involved in Antibodies Production of Rats with Collagen-Induced Arthritis via PI3KAkt-mTOR Signaling and the Regulation of Paeoniflorin. Journal of Ethnopharmacology, 141, 290-300. https://doi.org/10.1016/j.jep.2012.02.034

[14] King, D., Yeomanson, D. and Bryant, H.E. (2015) PI3King the Lock: Targeting the PI3K/Akt/mTOR Pathway as a Novel Therapeutic Strategy in Neuroblastoma. Journal of Pediatric Hematology/ Oncology, 37, 245-251. https://doi.org/10.1097/MPH.0000000000000329

[15] Thanaketpaisarn, O., Waiwut, P., Sakurai, H., et al. (2011) Artesunate Enhances Trail-Induced Apoptosis in Human Cervical Carcinoma Cells through Inhibition of the NFkappaB and PI3K/Akt Signaling Pathways. International Journal of Oncolo$g y, 39,279-285$.

[16] Wu, H.M., Tzeng, N.S., Qian, L., et al. (2009) Novel Neuroprotective Mechanisms of Memantine: Increase in Neurotrophic Factor Release from Astroglia and Anti-Inflammation by Preventing Microglial Activation. Neuropsychopharmacology, 34, 2344-2357. https://doi.org/10.1038/npp.2009.64

[17] Kamat, P.K., Rai, S., Swarnkar, S., Shukla, R., Ali, S., Najmi, A.K. and Nath, C. (2013) Okadaic Acid-Induced Tau Phosphorylation in Rat Brain: Role of NMDA Receptor. Neuroscience, 238, 97-113. https://doi.org/10.1016/j.neuroscience.2013.01.075

[18] Arif, M., Chikuma, T., Ahmed, M.M., et al. (2009) Effects of Memantine on Soluble Alphabeta(25-35)-Induced Changes in Peptidergic and Glial Cells in Alzheimer's Disease Model Rat Brain Regions. Neuroscience, 164, 1199-1209. https://doi.org/10.1016/j.neuroscience.2009.08.063

[19] Alley, G.M., Bailey, J.A., Chen, D., et al. (2010) Memantine Lowers Amyloid-Beta Peptide Levels in Neuronal Cultures and in APP/PS1 Transgenic Mice. Journal of Neuroscience Research, 88, 143-154. https://doi.org/10.1002/jnr.22172

[20] Arumugam, R., Natesan, V. and Mani, R. (2016) Effect of Naringin on Ammonium Chloride-Induced Hyperammonemic Rats: A Dose-Dependent Study. Journal of Acute Medicine, 6, 55-60. https://doi.org/10.1016/j.jacme.2016.08.001

[21] Li, Y., Su, R., Xu, S., Huang, Q. and Xu, H. (2017) Artesunate Prevents Rats from the Clozapine-Induced Hepatic Steatosis and Elevation in Plasma Triglycerides. Neuropsychiatric Disease and Treatment, 13, 2477-2487. https://doi.org/10.2147/NDT.S145069

[22] Cabuk, B., Etus, V., Bozkurt, S.U., et al. (2011) Neuroprotective Effect of Memantine on Hippocampal Neurons in Infantile Rat Hydrocephalus. Turkish Neurosurgery, 21, 352-358. https://doi.org/10.5137/1019-5149.JTN.4119-11.1

[23] Oikawa, K., Odero, G.L., Platt, E., et al. (2012) NF-kappaB p50 Subunit Knockout Impairs Late LTP and Alters Long Term Memory in the Mouse Hippocampus. BMC Neuroscience, 13, 45. https://doi.org/10.1186/1471-2202-13-45

[24] Kishida, K.T., Hoeffer, C.A., Hu, D., et al. (2006) Synaptic Plasticity Deficits and Mild Memory Impairments in Mouse Models of Chronic Granulomatous Disease. Molecular and Cellular Biology, 26, 5908-5920. https://doi.org/10.1128/MCB.00269-06

[25] Thippeswamy, A.H., Gollapalle, M.R. and Viswantha, L.S. (2013) Evaluation of Bacopa monnieri for Its Synergistic Activity with Rivastigmine in Reversing Aluminum-Induced Memory Loss and Learning Deficit in Rats. Journal of Acupuncture and Meridian Studies, 6, 208-213. https://doi.org/10.1016/j.jams.2013.02.004 
[26] Poirier, R., Cheval, H., Mailhes, C., et al. (2007) Paradoxical Role of an Egr Transcription Factor Family Member, Egr2/Krox20, in Learning and Memory. Frontiers in Behavioral Neuroscience, 1, 6. https://doi.org/10.3389/neuro.08.006.2007

[27] Waynforth, H.B. and Flecknell, P.A. (1998) Experimental and Surgical Technique in the Rat. Academic Press, London, San Diego.

[28] Ali, A.A., Ahmed, H.I. and Abu-Elfotuh, K. (2016) Modeling Stages Mimic Alzheimer's Disease Induced by Different Doses of Aluminum in Rats: Focus on Progression of the Disease in Response to Time. Journal of Alzheimer's Parkinsonism \& Dementia, 1, 002.

[29] Livak, K.J. and Schmittgen, T.D. (2001) Analysis of Relative Gene Expression Data Using Real-Time Quantitative PCR and the 2-Delta Delta C(T) Method. Methods (Scan Diego, Calif.), 25, 402-408. https://doi.org/10.1006/meth.2001.1262

[30] Schmittgen, T.D. and Livak, K.J. (2008) Analyzing Real-Time PCR Data by Comparative CT Method. Nature Protocols, 3, 1101-1108. https://doi.org/10.1038/nprot.2008.73

[31] Barnes, P. and Good, M. (2005) Impaired Pavlovian Cued Fear Conditioning in Tg2576 Mice Expressing a Human Mutant Amyloid Precursor Protein Gene. Behavioural Brain Research, 157, 107-117. https://doi.org/10.1016/j.bbr.2004.06.014

[32] Dong, H., Csernansky, C.A., Martin, M.V., Bertchume, A., Vallera, D. and Csernansky, J.G. (2005) Acetylcholinesterase Inhibitors Ameliorate Behavioral Deficits in the Tg2576 Mouse Model of Alzheimer's Disease. Psychopharmacology (Berl), 181, 145-152. https://doi.org/10.1007/s00213-005-2230-6

[33] Rather, M.A., Thenmozhi, A.J., Manivasagam, T., Bharathi, M.D., Essa, M.M. and Guillemin, G.J. (2018) Neuroprotective Role of Asiatic Acid in Aluminium Chloride Induced Rat Model of Alzheimer's Disease. Frontiers in Bioscience, Scholar, 10, 262-275. https://doi.org/10.2741/s514

[34] Liang, R.F., Li, W.Q., Wang, X.H., Zhang, H.F., Wang, H., Wang, J.X., et al. (2012) Aluminium-Maltolate-Induced Impairment of Learning, Memory and Hippocampal Long-Term Potentiation in Rats. Industrial Health, 50, 428-436. https://doi.org/10.2486/indhealth.MS1330

[35] Minkeviciene, R., Banerjee, P. and Tanila, H. (2004) Memantine Improves Spatial Learning in a Transgenic Mouse Model of Alzheimer's Disease. Journal of Pharmacology and Experimental Therapeutics, 311, 677-682. https://doi.org/10.1124/jpet.104.071027

[36] Van Dam, D., Abramowski, D., Staufenbiel, M. and De Deyn, P.P. (2005) Symptomatic Effect of Donepezil, Rivastigmine, Galantamine and Memantine on Cognitive Deficits in the APP23 Model. Psychopharmacology, 180, 177-190. https://doi.org/10.1007/s00213-004-2132-z

[37] Ahmed, H.H., Zaazaab, A.M. and Abd El-Motelp, B.A. (2014) Zingiber officinale and Alzheimer's Disease: Evidences and Mechanisms. International Journal of Pharmaceutical Sciences Review and Research, 27, 142-152.

[38] Creeley, C., Wozniak, D.F., Nardi, A., Farber, N.B. and Olney, J.W. (2008) Donepezil Markedly Potentiates Memantine Neurotoxicity in the Adult Rat Brain. Neurobiology of Aging, 29, 153-167. https://doi.org/10.1016/j.neurobiolaging.2006.10.020

[39] Van Den Herrewegen, Y., Denewet, L., Buckinx, A., et al. (2019) The Barnes Maze Task Reveals Specific Impairment of Spatial Learning Strategy in the Intrahippocampal Kainic Acid Model for Temporal Lobe Epilepsy. Neurochemical Research, 44, 600-608. https://doi.org/10.1007/s11064-018-2610-Z

[40] Sun, Z., Ma, Y., Chen, F., et al. (2018) Artesunate Ameliorates High Glucose-Induced 
Rat Glomerular Mesangial Cell Injury by Suppressing the TLR4/NF- $\kappa$ B/NLRP3 Inflammasome Pathway. Chemico-Biological Interactions, 293, 11-19. https://doi.org/10.1016/j.cbi.2018.07.011

[41] Decourt, B., Lahiri, D.K. and Sabbagh, M.N. (2017) Targeting Tumor Necrosis Factor Alpha for Alzheimer's Disease. Current Alzheimer Research, 14, 412-425.

[42] Italiani, P., Puxeddu, I., Napoletano, S., et al. (2018) Circulating Levels of IL-1 Family Cytokines and Receptors in Alzheimer's Disease: New Markers of Disease Progression? Journal of Neuroinflammation, 15, 342. https://doi.org/10.1186/s12974-018-1376-1

[43] Jangra, A., Kasbe, P., Pandey, S.N., Dwivedi, S., Gurjar, S.S., Kwatra, M., et al. (2015) Hesperidin and Silibinin Ameliorate Aluminum-Induced Neurotoxicity: Modulation of Antioxidants and Inflammatory Cytokines Level in Mice Hippocampus. Biological Trace Element Research, 168, 462-471. https://doi.org/10.1007/s12011-015-0375-7

[44] Zeng, J., Libien, J., Shaik, F., et al. (2016) Nucleolar PARP-1 Expression Is Decreased in Alzheimer's Disease: Consequences for Epigenetic Regulation of rDNA and Cognition. Neural Plasticity, 2016, Article ID: 8987928. https://doi.org/10.1155/2016/8987928

[45] Chang, T.Y., Yamauchi, Y., Hasan, M.T. and Chang, C. (2017) Cellular Cholesterol Homeostasis and Alzheimer's Disease. Journal of Lipid Research, 58, 2239-2254. https://doi.org/10.1194/jlr.R075630

[46] Ballard, C., Gauthier, S., Corbett, A., Brayne, C., Aarsland, D. and Jones, E. (2011) Alzheimer's Disease. The Lancet, 377, 1019-1031. https://doi.org/10.1016/S0140-6736(10)61349-9

[47] Brosseron, F., Krauthausen, M., Kummer, M. and Heneka, M.T. (2014) Body Fluid Cytokine Levels in Mild Cognitive Impairment and Alzheimer's Disease: A Comparative Overview. Molecular Neurobiology, 50, 534-544. https://doi.org/10.1007/s12035-014-8657-1

[48] Chen, S.L., Tao, P.L., Chu, C.H., et al. (2013) Low-Dose Memantine Attenuated Morphine Addictive Behavior through Its Anti-Inflammation and Neurotrophic Effects in Rats. Journal of Neuroimmune Pharmacology, 7, 444-453. https://doi.org/10.1007/s11481-011-9337-9

[49] Rai, S., Kamat, P.K., Nath, C., et al. (2013) A Study on Neuroinflammation and NMDA Receptor Function in STZ (icv) Induced Memory Impaired Rats. Journal of Neuroimmunology, 254, 1-9. https://doi.org/10.1016/j.jneuroim.2012.08.008

[50] Chong, T.W., Loi, S.M. and Lautenschlager, N.T. (2016) Therapeutic Advances and Risk Factor Management: Our Best Chance to Tackle Dementia? Medical Journal of Australia, 204, 91-92. https://doi.org/10.5694/mja15.01122

[51] Roussel, C., Caumes, E., Thellier, M., et al. (2017) Artesunate to Treat Severe Malaria in Travellers: Review of Efficacy and Safety and Practical Implications. Journal of Travel Medicine, 24. https://doi.org/10.1093/jtm/taw093

[52] Wen, Y., Pan, M.M., Lv, L.L., et al. (2018) Artemisinin Attenuates Tubulointerstitial Inflammation and Fibrosis via the NF- $\kappa$ B/NLRP3 Pathway in Rats with 5/6 Subtotal Nephrectomy. Journal of Cellular Biochemistry, 120, 4291-4300. https://doi.org/10.1002/jcb.27714

[53] Lai, L., Chen, Y., Tian, X., et al. (2015) Artesunate Alleviates Hepatic Fibrosis Induced by Multiple Pathogenic Factors and Inflammation through the Inhibition of LPS/TLR4/NF-kappaB Signaling Pathway in Rats. European Journal of Pharmacology, 765, 234-241. https://doi.org/10.1016/j.ejphar.2015.08.040 
[54] Cao, J., Wang, W., Li, Y., et al. (2016) Artesunate Attenuates Unilateral Ureteral Obstruction-Induced Renal Fibrosis by Regulating the Expressions of Bone Morphogenetic Protein-7 and Uterine Sensitization-Associated Gene-1 in Rats. International Urology and Nephrology, 48, 619-629. https://doi.org/10.1007/s11255-016-1232-0

[55] Cen, Y., Liu, C., Li, X., et al. (2016) Artesunate Ameliorates Severe Acute Pancreatitis (SAP) in Rats by Inhibiting Expression of Proinflammatory Cytokines and Toll-Like Receptor 4. International Immunopharmacology, 38, 252-260. https://doi.org/10.1016/j.intimp.2016.06.007

[56] Zeng, X.Z., Zhang, Y.Y. and Yang, Q. (2019) Artesunate Attenuates LPS-Induced Osteoclastogenesis by Suppressing TLR4/TRAF6 and PLC $\gamma 1-C a 2+-N F A T c 1$ Signaling Pathway. Acta Pharmaceutica Sinica. https://doi.org/10.1038/s41401-019-0289-6

[57] Kumar, A., Singh, A. and Ekavali (2015) A Review on Alzheimer's Disease Pathophysiology and Its Management: An Update. Pharmacological Reports, 67, 195-203. https://doi.org/10.1016/j.pharep.2014.09.004

[58] Qiao, G.H., Zhou, X.H., Zhang, H.S., Li, J.H., Wang, C.M., et al. (2011) Effect of Several Supplemental Chinese Herbs Additives on Rumen Fermentation, Antioxidant Function and Nutrient Digestibility in Sheep. Journal of Animal Physiology and Animal Nutrition, 96, 930-938. https://doi.org/10.1111/j.1439-0396.2011.01211.x

[59] Chu, W.B., Shi, B.L., Yan, S.M., Zhang, P.F., Zhao, F., Sun, D.S., et al. (2015) Effect of Artemisiaeargyi Extract on Immune and Antioxidative Function in Broilers. Chinese Journal of Animal Science, 51, 67-70.

[60] Zhang, D.H., Cheng, P.F. and Ling, L. (2011) Antioxidation and Genetic Toxicity of Artenisia Japonica Extract. Natural Product Research and Development, 23, 39-42.

[61] Lan, M.-B., Zhang, Y.-H., Zheng, Y., et al. (2010) Antioxidant and Immunomodulatory Activities of Polysaccharides from Moxa (Artemisia argyi) Leaf. The Food Science and Biotechnology, 19, 1463-1469. https://doi.org/10.1007/s10068-010-0209-5

[62] Niu, Q., Wang, L.P., Chen, Y.L. and Zhang, H.M. (2005) Relationship between Apoptosis of Rat Hippocampus Cells Induced by Aluminum and the Copy of the bcl-2 as Well as Bax mRNA. Journal of Hygiene Research, 34, 671-673.

[63] Zhang, H., Zhang, Y.W., Chen, Y., Huang, X., Zhou, F., et al. (2012) Appoptosin Is a Novel Pro-Apoptotic Protein and Mediates Cell Death in Neurodegeneration. Journal of Neuroscience, 32, 15565-15576. https://doi.org/10.1523/JNEUROSCI.3668-12.2012

[64] Ghribi O., Herman, M.M. and Savory, J. (2002) The Endoplasmic Reticulum Is the Main Site for Caspase-3 Activation Following Aluminum-Induced Neurotoxicity in Rabbit Hippocampus. Neuroscience Letters, 324, 217-221. https://doi.org/10.1016/S0304-3940(02)00147-7

[65] Hampel, H., Prvulovic, D., Teipel, et al. (2011) The Future of Alzheimer's Disease: The Next 10 Years. Progress in Neurobiology, 95, 718-728.

https://doi.org/10.1016/j.pneurobio.2011.11.008

[66] Verstraeten, S.V., Aimo, L. and Oteiza, P.I. (2008) Aluminium and Lead: Molecular Mechanisms of Brain Toxicity. Archives of Toxicology, 82, 789-802. https://doi.org/10.1007/s00204-008-0345-3

[67] Ghavami, S., Shojaei, S., Yeganeh, B., Ande, S.R., Jangamreddy, J.R., Mehrpourg, M., et al. (2014) Autophagy and Apoptosis Dysfunction in Neurodegenerative Dis- 
orders. Progress in Neurobiology, 112, 24-49.

https://doi.org/10.1016/j.pneurobio.2013.10.004

[68] Ilamathi, M., Prabu, P.C., Ayyappa, K.A., et al. (2016) Artesunate Obliterates Experimental Hepatocellular Carcinoma in Rats through Suppression of IL-6-JAK-STAT Signalling. Biomedicine \& Pharmacotherapy, 82, 72-79.

https://doi.org/10.1016/j.biopha.2016.04.061

[69] Yu, L., Chen, J.F., Shuai, X., et al. (2016) Artesunate Protects Pancreatic Beta Cells against Cytokine-Induced Damage via SIRT1 Inhibiting NF- $\kappa$ B Activation. Journal of Endocrinological Investigation, 39, 83-91. https://doi.org/10.1007/s40618-015-0328-1

[70] Nobakht, M., Hoseini, S.M., Mortazavi, P., Sohrabi, I., Esmailzade, B., Rahbar Rooshandel, N. and Omidzahir, S. (2011) Neuropathological Changes in Brain Cortex and Hippocampus in a Rat Model of Alzheimer's Disease. Iranian Biomedical Journal, 15, 51-58.

[71] Said, M.M. and Abd Rabo, M.M. (2017) Neuroprotective Effects of Eugenol against Aluminium-Induced Toxicity in the Rat Brain. Arhiv za Higijenu Rada i Toksikologiju, 68, 27-37. https://doi.org/10.1515/aiht-2017-68-2878

[72] Valizadeh, K., et al. (2016) Gallicacid Effect on Dementia Type of Alzheimer Disease. Basic and Clinical Neuroscience, 7, 97-106.

[73] Babu, S.M., Swain, S. and Boyapati, P. (2016) Neuroprotective Activity of Ethanolic Extract of Tamarindus indica Seeds against Aluminium Induced Neurotoxicity. Asian Journal of Pharmaceutical and Health Sciences, 6, 1445-1452.

[74] Al-Bishri, W.M., Hamza, A.H. and Farran, S.K. (2017) Resveratrol Treatment Attenuates Amyloid Beta, Tau Protein and Markers of Oxidative Stress, and Inflammation in Alzheimer's disease Rat Model. International Journal of Pharmaceutical Research and Allied Sciences, 6, 71-78. 


\section{Abbreviations}

AD: Alzheimer's Disease

$\mathrm{A} \beta$ : Amyloid $\beta$

NFTs: Neurofibrillary Tangles

$\mathrm{AlCl}_{3}$ : Aluminum Chloride

MWM: Morris Water Maze

IAL: Initial Acquisition Latency

RL: Retention Latency

ELISA: Enzyme-Linked Immunosorbent Assay

TNF- $\alpha$ : Tumor Necrosis Factor Alpha

IL-1 $\beta$ : Interleukin- 1 Beta

qRT-PCR: Quantitative Reverse Transcription Polymerase Chain React Ion RQ: Relative Quantification

iNOS: Inducible Nitric Oxide Synthase 